\title{
Group Decision Using Analytical Hierarchical Process: Surabaya's Universities Library in Digital Natives Perspective
}

\author{
S. Halim ${ }^{1}$, Felecia ${ }^{1}$, D. Wulandari ${ }^{2}$, F.L. Susanti ${ }^{1}$ \\ ${ }^{1}$ Department of Industrial Engineering, Petra Christian University, Surabaya, Indonesia \\ ${ }^{2}$ Library Petra Christian University, Surabaya, Indonesia \\ (halim@petra.ac.id, felecia@petra.ac.id, dian@petra.ac.id, fransiscalucy.susanti@gmail.com)
}

\begin{abstract}
In recent years the numbers of out of shelves books in the Surabaya's universities library is decreasing. This is not a surprising phenomenon. The digital natives, as the primary customers of the library, are generation which always connect to the world through their gadgets. Library which in the past was the solely place for searching the information is no longer the source of finding the information. Using analytical hierarchy process for groups, we investigated the representative library of the digital natives, particularly in six universities in Surabaya. Additionally, we also proposed a correction to the geometric mean which usually used to represents the scale for the group.

Keywords - Analytical hierarchy process, group decision, digital natives, library.
\end{abstract}

\section{INTRODUCTION}

Library which in the past was the place for searching information, now is no longer as the only place for finding the information. Internet has taken the primary library role as the source for finding the information. Therefore, no surprisingly that the numbers of out of shelves books, particularly in Surabaya universities library is decreasing [1]. The digital natives, which are the main customers of the library needs library not only as a place for borrowing books. They needs library which represented the characteristic of the digital natives [2, 3].

Digital native is the generation which is born after 1994 [4] and "native" in the language of computers, social media and other sites on the internet [5]. They gather information through their gadget which they can connected to the internet easily. They are nontraditional learners [6]. Their literacy to the digital world are very high. Oblinger and Oblinger [6] stated the characteristics of this generation, not only digital literate, they are also connected, immediate, experiential, prolific communicators (social), work in a team, their preference is for structure rather than ambiguity, oriented toward making observations, visual and kinesthetic, take part in the community activities.

We have surveyed 460 students in six biggest universities in Surabaya about their needs of library and what kind of library' features that represent digital natives' characteristic. The finding of the previous studies: the library is still needed, but the functions are not solely for borrowing books. Library should also be a place for leisure and discussion [2,3]. Continuing, the finding in the previous studies, in this research we examine their preferences in detail. We surveyed 317 students in the same universities as be studied before. In this survey, we asked them to do pairwise comparisons for each library features so that we can know the ranking of their needs. Additionally, we used the Analytical Hierarchical Process [7] for group decision makers.

\section{METHODOLOGY}

The Analytic Hierarchy Process (AHP) is a theory of relative measurement with absolute scale of both tangible and intangible criteria based on the judgment of knowledgeable and expert people [7]. In the AHP the judgments are made by comparing many criteria in reciprocal pairwise. The fundamental scale that use in AHP can be seen in Table 1 .

TABLE I

FUNDAMENTAL SCALE

\begin{tabular}{ll}
\hline 1 & equal importance \\
3 & moderate importance of one over another \\
5 & strong or essential importance \\
7 & very strong or demonstrated importance \\
9 & extreme importance \\
$2,4,6,8$ & Intermediate values \\
Use reciprocals for inverse comparisons \\
\hline
\end{tabular}

In our case we only used 3, 5, 7 and 9 scaling with their respective reciprocals for the inverse comparisons. We remove the number 1 in the fundamental scaling, so that there will be no equal importance in comparing all criteria.

In a single decision maker, we let $X=\left(x_{1}, x_{2}, \ldots, x_{n}\right)$ is a finite set of $n$ alternative. A decision maker compares each alternative pair wisely, e.g. $x_{1}$ to $x_{2}$ and gives a certain scaling number for example $a_{12}$ as his or her decision. The pairwise comparisons are collected into a pairwise comparison matrix. In this matrix the lower triangular of the matrix is reciprocal to the upper triangular and the diagonal matrix equal to one. Let $a_{k l}$ is the element of matrix $\boldsymbol{A}$

$$
\boldsymbol{A}=\left(\begin{array}{cccc}
1 & a_{12} & \ldots & a_{1 n} \\
1 / a_{12} & 1 & \ldots & a_{2 n} \\
\vdots & \vdots & \ddots & \vdots \\
1 / a_{1 n} & 1 / a_{2 n} & \ldots & 1
\end{array}\right)
$$

Once a pairwise comparison matrix is completed, we can derive the priority vector $\boldsymbol{w}=\left(w_{1}, w_{2}, \ldots, w_{n}\right)$ using for example normalized principal eigen vector of matrix $\boldsymbol{A}$ [8].

In a group decision makers, the scale for each criteria from 
all members in a group is represented by the geometric mean of the individual scales.

Let $X_{j}=\left(x_{1 j}, x_{2 j}, \ldots, x_{n j}\right), j=1, \ldots, m$ is a finite set of $n$ alternative which is given to decision maker $j$. Let $m$ is the number of decision makers in a group.

$a_{k l}^{j}$ is a scale given by decision maker $j$ on when he or she compares alternative $x_{k}$ to $x_{l}$. The scale's geometric mean which represent the group of decision makers can be written as

$$
\tilde{a}_{k l}=\sqrt[m]{\prod_{j=1}^{m} a_{k l}^{j}}
$$

Since the individual scale which is given by for example two decision makers can be reciprocal to each other, for example $a_{12}^{1}=9, a_{12}^{2}=1 / 9$ then multiplying those two scales will give 1 as a result. If many scaling are reciprocal to each other then (1) can be written as

$$
\tilde{a}_{k l}=\sqrt[m]{\prod_{j=1}^{m_{1}} a_{k l}^{j} \prod_{1}^{m_{2}} 1}
$$

where $m_{1}<m ; m_{2}$ is the number of pairs which are reciprocal to each other and $a_{k l}^{j}$ are not reciprocal to each other. We then can write (2) as

$\tilde{a}_{k l}=\sqrt[m]{\prod_{j=1}^{m_{1}} a_{k l}^{j}}$ as $m \rightarrow \infty$ then $\tilde{a}_{k l} \rightarrow 0$

To avoid (3), we then preprocessed the individual scale and removed the scales that reciprocal to each other. The preprocessing step can be done by constructing frequency table of each answer for each criteria.

TABLE II

SCALING FREQUENCY TABLE

\begin{tabular}{lc}
\hline Scale & Frequency \\
\hline $1 / 9$ & $f_{1 / 9}$ \\
$1 / 7$ & $f_{1 / 7}$ \\
$1 / 5$ & $f_{1 / 5}$ \\
$1 / 3$ & $f_{1 / 3}$ \\
3 & $f_{3}$ \\
5 & $f_{5}$ \\
7 & $f_{7}$ \\
9 & $f_{9}$ \\
\hline
\end{tabular}

$f_{s}$ is the frequency at scaling number $s$

Supposing $f_{9}>f_{1 / 9}$ then $f_{9}-f_{1 / 9}=f_{9}^{*}$ is the new frequency of the scale 9 , and the $f_{1 / 9}=0$. Since the scale 9 and $1 / 9$ is reciprocal to each other the product of $f_{1 / 9}$ pairs of these two scales will equal to one. Doing this step to the other reciprocal pairs then we will have the new frequency table. Calculate the new geometric mean using this table.
Suppose $f_{9}>f_{1 / 9} ; f_{7}<f_{1 / 7} ; f_{5}>f_{1 / 5} ; f_{3}=f_{1 / 3}$ we then have $f_{9}^{*} ; f_{1 / 7}^{*} ; f_{5}^{*}$ and $m_{1}=f_{9}^{*}+f_{1 / 7}^{*}+f_{5}^{*}$

The new geometric mean will be:

$$
\begin{aligned}
& \tilde{a}_{k l}=\sqrt[m_{1}]{\prod_{1}^{f_{9}^{*}} 9 \prod_{1}^{f_{1 / 7}^{*}} 1 / 7 \prod_{1}^{f_{5}^{*}} 5} \text { or } \\
& \tilde{a}_{k l}=\sqrt[m_{1}]{(9)^{f_{9}^{*}}(1 / 7)^{f_{1 / 7}^{*}(5)^{f_{5}^{*}}}}
\end{aligned}
$$

For now on, in this paper we use

$$
\tilde{a}_{k l}=\sqrt[m_{1}]{\prod_{j=1}^{m_{1}} a_{k l}^{j}}
$$

as the geometric mean to represent the group decision.

The geometric consistency index [9] for the $j$-th decision maker is formulated as:

$G C I^{j}=\frac{1}{\left(n_{-1}\right)(n-1)} \sum_{k<l}\left(\log e_{k l}^{j}\right)^{2}$

where

$e_{k l}^{j}=a_{k l}^{j} \frac{w_{k}^{j}}{w_{l}^{j}}$ for $1 \leq k, l \leq n ;$

$a_{k l}^{j}$ is the element of the comparison matrix $A_{j}$ and $w_{k}^{j}$ is the priority weight of criteria $k$ from decision makers $j$. Note instead of $m$ decision makers, we only use instead of $m_{1}$. Aguaron and Jimenes [10] suggested that for comparison matrices with size $m=3$, the threshold is 0.31 , for $m=4$, the threshold is 0.35 ; and when $m>4$, the threshold is 0.37 . If the $G C I^{j}$ is less than the corresponding threshold, then the comparison matrix of the $\mathrm{j}$-th decision maker will pass the consistency test.

The consistency index of pair wise comparison matrix is given by $C . I=\left(\lambda_{\max }-n\right) /(n-1), \lambda_{\max }$ is the $\max$ eigen value of the respective matrix (for the detail see [11]).

\section{RESULTS}

\section{A. Data}

This research was conducted in six universities in Surabaya. The three of those universities are state universities, i.e., Institute Technology of Sepuluh Nopember (ITS) 50 respondents, Airlangga University (Unair) 56 respondents, Universitas Pembangunan Nasional (UPN) 27 respondents, and three of them are private university: Petra Christian University (PCU) 114 respondents, University of Surabaya (Ubaya) 50 respondents and Widya Mandala Catholic University (UWM) 20 respondents. They are active students and most of them are class 2015 (32\%), class 2014 (24\%), 23\% class of 2013, and the rest are from class 2010-2012. Most of the respondents are female (62\%) and male (38\%) see Fig. 1.

\section{B. The Model}

The model was constructed via focus group discussion (FGD) between the heads of the libraries from ITS, Ubaya, UKP and Surabaya city-library [2]. Besides the FGD, we also did open-survey to 100 students from those six 


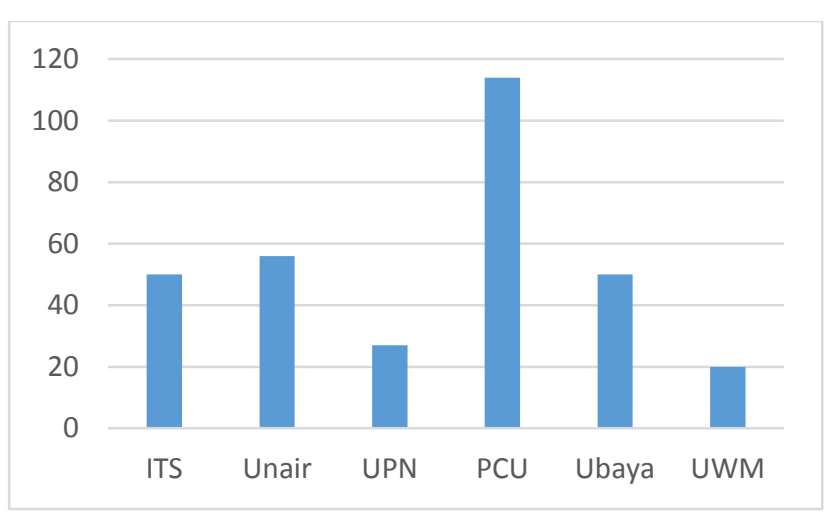

Fig.1 The distribution of the university respondents in this study.

universities, questioning what kind of facilities that they hope are provided by the library. The summary of the FGD and the open survey is depicted in the AHP model (Fig. 2)

\section{Priorities}

The students as the decision makers in this research, particularly study in state universities (ITS, Unair, UPN) and private universities (PCU, Ubaya and UWM). Regardless of the status of the university, the Top priority on each criteria for them are the books are up to date, fast wi-fi access, the library is comfortable (i.e. clean and air conditioning) and the staffs are helpful. The complete list of the ideal library according to them is summarized in Table III.

TABLE III

LIBRARY BASED ON STUDENT'S PRIORITY

\begin{tabular}{lll}
\hline Criteria & \multicolumn{2}{l}{ Priority } \\
\hline Book Collection & 1. The books are up to date \\
& 2. Provide reference text-books \\
& 3. Online collections \\
\hline Technology & 1. Fast Wi-fi access \\
& 2. Easiness to access the digital \\
& 3. Collections / journal \\
& & Catalog online and library \\
\hline Facilities & 1. Comfortable \\
& 2. Leisure place/carpeted rooms. \\
& 3. Has discussion rooms. \\
& 4. Has many electric plugs \\
& 5. Library café \\
& 6. Private reading rooms \\
& 7. Sofa \\
& 8. Interesting interior design \\
& 9. Mini theater \\
\hline Services & 1. The staffs are helpful \\
& 2. Operational hours \\
& 3. The staffs are informative. \\
\hline
\end{tabular}

The student's priorities in these criteria: Book collection, Technology and Services are the same either they are from state or private universities. But those priorities are different, when those two groups of students decided the ideal facilities for the library. For state universities the top three facilities that they need for the library are comfortable, has a leisure place with carpeted room so that they can study and have discussion on the floor, and the library has rooms for serious discussion. However, for the private universities students, the top three priorities for them are the library should have rooms for serious discussion, it should be comfortable (clean and air conditioning) and have leisure room. The complete list of ideal library facilities according to the state and private universities is given in Table IV.

TABLE IV

LIBRARY FACILITES ON THE STATE UNIVERSITIES AND PRIVATE UNIVERSITIES PERSPECTIVE

\begin{tabular}{l|l}
\hline \multicolumn{1}{c|}{ State Universities } & \multicolumn{1}{|c}{ Private Universities } \\
\hline 1.Comfortable & 1. Has discussion rooms \\
2. Leisure room/carpeted & 2. Comfortable \\
rooms & 3. Leisure room/carpeted \\
3.Has discussion rooms. & rooms \\
4. Has many electricity & 4. Has many electricity \\
plugs & plugs \\
5.Library café & 5. Library café \\
6.Private reading rooms & 6. Private reading rooms \\
7.Sofa & 7. Sofa \\
8. Interesting interior & 8. Interesting interior \\
design & design \\
9.Mini theater & 9. Mini theater \\
\hline
\end{tabular}

\section{DISCUSSION}

This study was conducted using AHP for group decision makers. We calculated the weighted priorities vectors using super-decision software [12]. Additionally to the geometric-mean that usually used as the representative scaling for a group decision makers, we proposed a preprocessing step before directly apply the geometric mean. The proposed preprocessing will avoid us to get a geometric means that close to 0 .

There are many ways to represent the scaling and the consistency index for groups of decision makers. We will explore those methods and find new proposed methods in our future research.

\section{CONCLUSION}

In the previous study we found that library is still needed by the digital natives, but now the function is not solely as a place for borrowing books. In this research, we questioning them what kind of facilities in the library that they really want to be there. Using AHP, we found those priorities.

For the next research, we are going to use the finding of this research for designing a library for the digital native, particularly for the digital natives in Surabaya. 


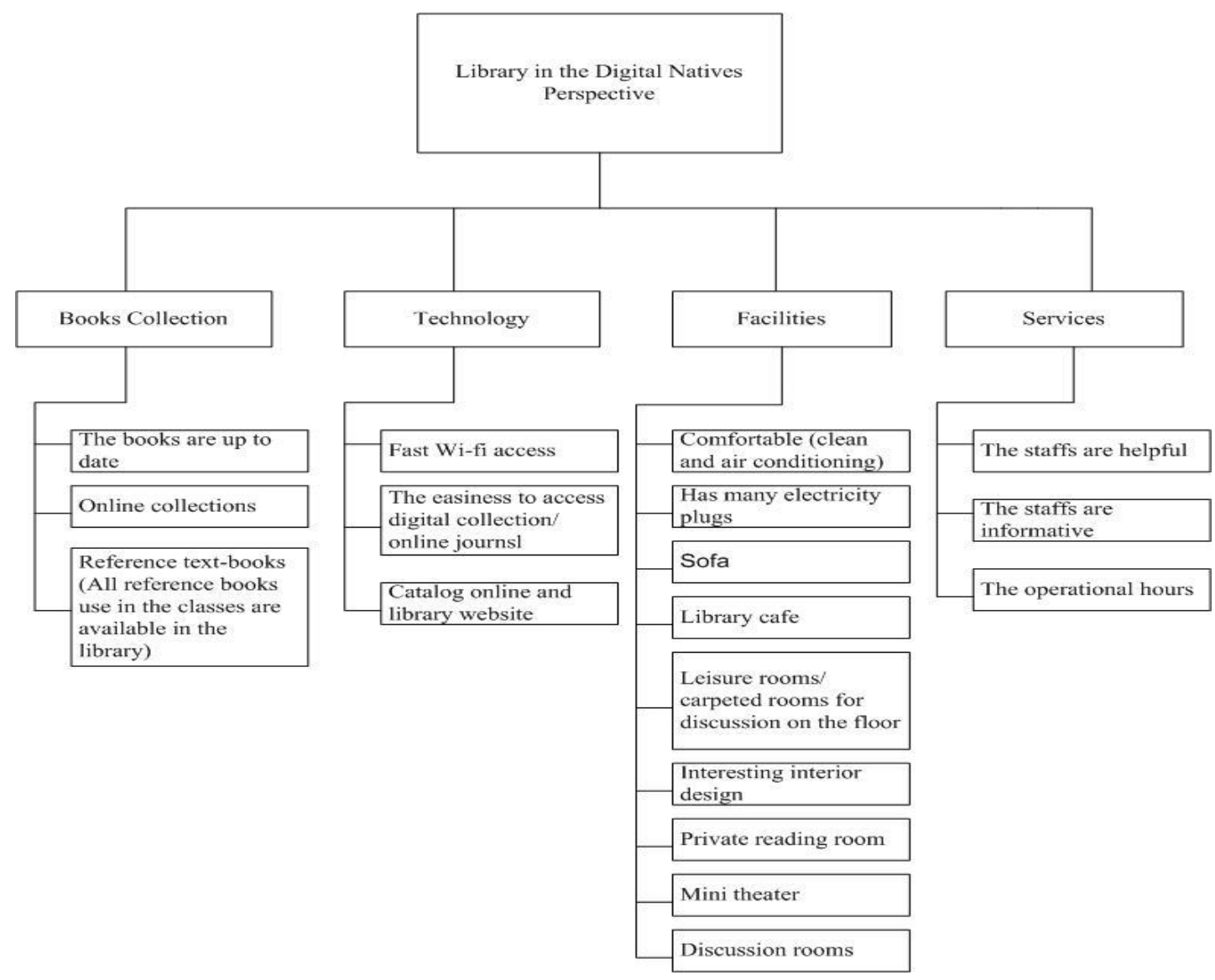

Fig. 2 The AHP model for the library

\section{ACKNOWLEDGMENT}

This research was financially supported by the Indonesian Ministry of Research and TechnologyDirectorate of High Education (Kemenristek-DIKTI):

\section{REFERENCES}

[1] D. Wulandari, S. Halim, and A. Nugraha, Analisa Faktorfaktor yang mempengaruhi minat berkunjung mahasiswa ke perpustakaan UK. Petra Surabaya, Research Report, LPPMUK. Petra, 2012

[2] S. Halim, D. Wulandari, D., D.K.F., Sopacua, , Felecia and Inggrid, "Library for the digital natives: What to do", Proceeding of International Conference on Record and Library, Universitas Airlangga, Surabaya 10-11 Oct 2015.

[3] S. Halim, Felecia, Inggid, D. Wulandari, and D.K.F. Sopacua, "Digital natives: Its characteristics and challenge to the library service quality", Proceedings of Second International Conference on Electrical Systems, Technology and Information (ICESTI 2015), Springer, Lecture Notes in Electrical Engineering, January 2016, Volume 365, pp. 487-494.
[4] M. Prensky, "Digital natives, digital immigrants", On the Horizon, vol 9, no. 5, pp. 1-6, October 2001.

[5] J.K. Lippincot, "Net generation and libraries, in educating the net generation. [Online]. Available: http://www.educause.edu/educatingthenetgen/

[6] D.G. Oblinger and J.L Oblinger, "Is it age or IT: First steps toward understanding the net generation in educating the Net Generation. [Online]. Available: $\mathrm{http} / / / \mathrm{www}$.educause.edu/educatingthenetgen

[7] T.L. Saaty,"Decision making with the analytical hierarchy process", International Journal of Service Science, vol.1, no.1, pp. 83-98,2008.

[8] M. Brunelli, "Introduction to the Analytic Hierarchy Process", SpringerBriefs in Operations Research, P.83.978-3$319=12502-2,2015$

[9] G. Crawford and C. William, "A Note on the analysis of subjective judgment matrices", Journal of Mathematical and Psuchology, 29, pp. 387-405, 1985.

[10] M. J. Jimenez, J. A., Joven, A. R., Pirla, A.T. Lanuza, “A spreadsheet module for consistent consensus building in AHP-group decision making", Group Decision Negotiation, 14,pp 89-108, 2005

[11]T.L. Saaty, "The Analytic Hierarchy Process", Mac. GrawHill New York, 1980

[12]ANP team, "Superdecision-Software", [online] available: http://www.superdecisions.com/ 